\title{
LIMB-GIRDLE MUSCULAR DYSTROPHY TYPE 2B MIMICKING POLYMYOSITIS
}

\author{
Leonardo Halley Carvalho Pimentel', Raimundo Neudson Maia Alcântara², \\ Sheila Márcia de Araújo Fontenele ${ }^{2}$, Carlos Maurício de Castro Costa, , \\ Francisco de Assis Aquino Gondim ${ }^{1,2}$
}

Limb-girdle muscular dystrophy (LGMD) type $2 \mathrm{~B}$ is caused by mutations in the dysferlin gene, located at cromossome 2p13.1-p13.3. This protein is normally expressed at the skeletal muscle, but in affected patients it is reduced or absent'. Disferlinopathies usually manifest in late adolescence or early adulthood. The progression is usually slow and most of the patients lose their ability to walk in the second decade or later ${ }^{2}$. Variability in the clinical phenotype within the family has been described, following a recessive inheritance pattern ${ }^{2}$. Muscle biopsy findings in LGMD type $2 \mathrm{~B}$ can reveal significant inflammatory changes, which can be occasionally confused with those seen in polymyositis and delay the correct diagnosis.

We present the case of a patient with LGMD 2B misdiagnosed as polymyositis to further illustrate these diagnostic challenges. Informed consent in writing was obtained from our patient.

\section{CASE}

A 58-year-old woman developed slowly progressive proximal weakness in the lower limbs, which started in her third decade of life and later progressed to the upper extremities. EMG revealed a myopathy with abundant spontaneous activity and a muscle biopsy from 1995 revealed endomysial and perivascular inflammation. Polymyositis was diagnosed and high-dose prednisone was started. The patient experienced no improvement despite treatment for several years. In 2001 she was started on azathioprine.

In 2004, she underwent a new neurological evaluation. Her neurological exam revealed normal mental status and cranial nerves evaluation, hypoactive reflexes, proximal weakness (grade 2 in the proximal lower extremities and 4 in the arms), normal sensory and cerebellar testing, waddling gait with pronounced lordosis, inability to stand up from a chair without support. Slight atrophy in the proximal legs was noted. A neuropsychological evaluation was unremarkable. Her family history was significant for several reasons. First, her parents were second-degree cousins. Second, she reported that among her six brothers and sisters, two of them had a disease that resembled her condition. There were no other similar cases in the family, except for the daughter of one of the brothers, who started to subjectively complain of gait difficulties. In a second evaluation, she brought one of her brothers who had similar disease pattern. A familial LGMD was suspected. EMG confirmed the presence of a myopathy with abundant spontaneous activity, also involving the proximal upper extremities. The serum aldolase and creatine kinase levels were markedly elevated (15.6U/L and 2234UI/L respectively). Azathioprine was discontinued and prednisone was slowly tapered off. A new muscle biopsy was performed. It revealed dystrophic features and perivascular inflammation (Figure). Immunohistochemistry, which included identification of dystrophin, merosin, calpain, calveolin, alpha, beta, gamma and delta sarcoglycans and dysferlin staining demonstrated absence of dysferlin in skeletal muscle (Figure).

The diagnosis of LGMD type 2B was made. Prednisone was completely stopped after being slowly tapered off. Evaluation of the other symptomatic brothers revealed similar conditions. The youngest was 45-year-old and had fatigue and progressive muscle weakness for 20 years. Motor examination revealed proximal weakness and slight atrophy in the legs. Serum aldolase and creatine kinase levels were $31.0 \mathrm{U} / \mathrm{L}$ and $3990 \mathrm{UI} / \mathrm{L}$ respectively. The oldest is 66 years old and reported muscular weakness in lower limbs since he was 50 years old. After five years he was aware of decreased strength in upper limbs. He became wheelchair-bound in the last 4 years.

\section{DISCUSSION}

The term LGMD encompasses distinct disorders, most of them characterized by proximal muscular weakness. The autosomal dominant LMGDs are named type 1 and the autosomal recessives type 2 . Subclassification with an alphabetical letter characterizes different genetic forms

DISTROFIA MUSCULAR DE CINTURAS TIPO 2B SIMULANDO POLIMIOSITE

'Departamento de Fisiologia e Farmacologia, Universidade Federal do Ceará, Fortaleza CE, Brazil; ${ }^{2}$ Hospital Universitário Walter Cantídio, Universidade Federal do Ceará, Fortaleza CE, Brazil.

Received 1 August 2007, received in final form 23 October 2007. Accepted 7 December 2007.

Dr. Francisco de Assis Aquino Gondim - Universidade Federal do Ceará / CP 3157 - Rua Cel Nunes de Melo 1127 - 60430-270 Fortaleza CE - Brasil. E-mail: gondimfranc@yahoo.com 

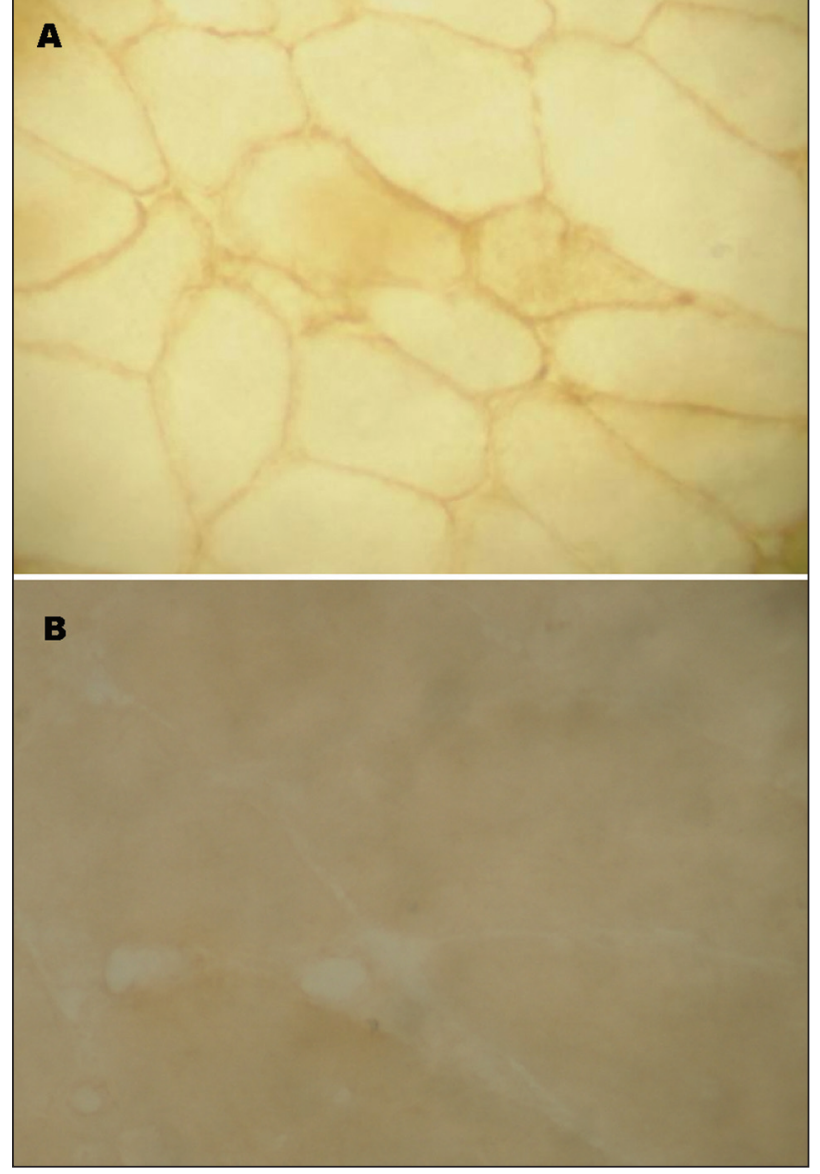

Figure. (A) Dysferlin in sarcolemma of a normal muscle fiber (control). (B) Absence of dysferlin in an abnormal muscle fiber from our patient.

of LGMD 1 and LGMD 2. The recessive forms are more common than the dominant ones ${ }^{2,3}$.

Mutations in the dysferlin gene are associated with LGMD type 2B, Miyoshi myopathy and distal anterior compartment myopathy. Dysferlin was proposed to have a functional role in mediating the fusion of intracellular vesicles to the sarcolemma during injury-induced membrane repair, but dysferlin has been found not only at the sarcolemma but also within the cytoplasm of skeletal muscle fibers by immunohistochemistry ${ }^{4}$. The process underlying the pathogenetic mechanism of dysferlinopathy is not completely understood, but it is know that dysferlin plays an essential function in muscle fiber repair ${ }^{5}$. Defects of dysferlin has been suspected in older mices with inflammatory changes in skeletal muscle 6 . The question whether there could be a natural reduction of dysferlin in muscles throughout life is open and demands further investigation.

Dysferlin was also demonstraded by Western blot in human and mouse brains, but there is little knowledge about its function in the brain or its role in neurodegenerative diseases. There is evidence of accumulation of dysferlin in the Alzheimer disease brain, which may be related to the inability of neurons to repair damage due to $\beta$-amiloid deposits accumulating in this disease ${ }^{7}$.

The classical phenotype of LGMD type $2 B$ is proximal muscular weakness and atrophy, but some phenotypic variants of this disease and others dysferlinopathies have been described ${ }^{1,8,9}$. Some of them are associated with new mutations in the dysferlin gene ${ }^{10}$. Recently, a patient with LGMD type $2 B$ was reported with choreic movements, suggesting central nervous system involvement and altered expression of the brain isoform of dysferlin".

In our patient, the family history suggests autosomal recessive inheritance because her parents were seconddegree cousins. However, it is surprising that among seven brothers three are probably affected (including the patient). The patient's family has native American Indian phenotypic traits. To our knowledge, there is no report of other cases of LGMD type 2B in native American Indian descendents. Perhaps a new mutation may justify the high penetrance of dysferlin gene in this family, but further genetic evaluation is necessary to prove this hypothesis.

Muscle biopsies in LGMD type 2B are characterized by dystrophic changes in affected muscles. The occasional finding of endomysial or perivascular inflammation is possible and may lead towards a wrong diagnosis of polymyositis. The muscle biopsy is the most important test to determine the diagnosis of inflammatory myopathies, but also the most common cause of misdiagnosis due to incorrect interpretation ${ }^{12}$. There is a recent report of a patient diagnosed with polymyositis and associated autoimmune Addison's disease and sarcoidosis, which was subsequently found to be a LGMD $2 B^{13}$. Perhaps dysferlin deficiency can have some kind of association with autoimmunity. Other authors suggest that splice site mutations that disrupt dysferlin may produce a phenotype associated with muscle inflammation ${ }^{14}$.

Muscle biopsy has great value in the diagnosis of LGMD $2 \mathrm{~B}$ diagnosis $^{15}$ and can demonstrate a membrane attack complex on the sarcolemma of non-necrotic muscle fibers. This feature is also seen in other dystrophies with secondary inflammation, but not in primary inflammatory myopathies like polymyositis ${ }^{16}$. Absent or very faint bands of dysferlin are observed in muscle biopsies of patients with LGMD type $2 \mathrm{~B}$ by immunohistochemistry and Western blot ${ }^{17}$.

In conclusion, LGMD 2B and other types of LGMD (especially recessive forms) can mimic primary inflammatory myopathies. Steroids and immunossupressant treatments are ineffective in LGMD and may have several adverse effects. The differentiation between these two entities and correct diagnosis are important to avoid these side effects of unnecessary therapy. 


\section{REFERENCES}

1. Prelle A, Sciacco M, Tancredi L, et al. Clinical, morphological and immunological evaluation of six patients with dysferlin deficiency. Acta Neuropathol 2003;105:537-542.

2. Amato AA, Brooke MH. Disorders of skeletal muscle. In Bradley WG, Daroff RB, Fenichel GM, et al (Eds). Neurology in clinical practice. $4^{\text {th }}$ Ed. Philadelphia: Butterworth-Heinemann 2004:2463-2510.

3. Pramono ZA, Lai PS, Tan CL, Takeda S, Yee WC. Identification and characterization of a novel human dysferlin transcript: dysferlin_v1. Hum Genet 2006;120:410-419.

4. Ampong BN, Imamura M, Matsumiva T, Yoshida M, Takeda S. Intracellular localization of dysferlin and its association with the dihydropyridine receptor. Acta Myol 2005;24:134-144.

5. Cenacchi G, Fanin M, De Giorgi LB, Angelini C. Ultrastructural changes in dysferlinopathy support defective membrane repair mechanism. J Clin Pathol 2005;58:190-195.

6. Nemoto H, Konno S, Nakazora H, Miura H, Kurihara T. Histological and immunohistological changes of the skeletal muscles in older SJL/ J mices. Eur Neurol 2007;57:19-25.

7. Galvin JE, Palamand D, Strider J, Milone M, Pestronk A. The muscle protein dysferlin accumulates in the Alzheimer brain. Acta Neuropathol 2006;112:665-671.

8. Nguyen K, Bassez G, Bernard R, et al. Dysferlin mutations in LGMD2B, Miyoshi myopathy and atypical dysferlinopathies. Hum Mutat 2005;26:165.
9. Kawabe K, Goto K, Nishino I, Angelini C, Hayashi YK. Dysferlin mutation analysis in a group of Italian patients with limb-girdle muscular dystrophy and Miyoshi myopathy. Eur J Neurol 2004;11:657-661.

10. Vilchez JJ, Gallano P, Gallardo E, et al. Identification of a novel founder mutation in the DYSF gene causing clinical variability in the Spanish population. Arch Neurol 2005;62:1256-1259.

11. Takahashi T, Aoki M, Imai T, et al. A case of dysferlinopathy presenting choreic movements. Mov Disord 2006;21:1513-1515.

12. Dalakas MC, Hohlfeld R. Polymyositis and dermatomyositis. Lancet 2003;362:971-982

13. Selva-O 'Callaghan A, Labrador-Horrilo M, Gallardo E, Herruzo A, Grau-Junyent JM, Vilardell-Tarres M. Muscle inflammation, autoimmune Addison`s disease and sarcoidosis in a patient with dysferlin deficiency. Neuromuscul Disord 2006;16:208-209.

14. McNally EM, Ly CT, Rosenmann H, et al. Splicing mutation in dysferlin produces limb-girdle muscular dystrophy with inflammation. Am J Med Genet 2000;91:305-312.

15. Comerlato EA, Scola RH, Werneck LC. Limble-girdle muscular dystrophy: an immunohistochemical diagnostic approach. Arq Neuropsiquiatr 2005;63:235-245.

16. Spuler S, Engel AG. Unexpected sarcolemmal complement membrane attack complex deposits on non-necrotic muscle fibers in muscular dystrophies. Neurology 1998;50:41-46.

17. Fanin M, Pegoraro E, Matsuda-Asada C, Brown RH, Angelini C. Calpain-3 and dysferlin protein screening in patients with limb-girdle dystrophy and myopathy. Neurology 2001;56:660-665. 